\title{
A Clinical Trial for Studying the Effect of Jojoba Oil Rectal Suppositories in Treatment of Anal Fissure
}

\author{
Hassan Z. Shaker, MD, FACS, FICS; Hanna Habib, MD; Ashraf Hegab, MD; Wafi Fouad Salib, MD \\ Department Of General Surgery, Ain Shams University, Egypt
}

\section{Introduction}

Anal fissure is one of the most common surgical problems world-wide. Different treatment modalities have been evolved.

Conservative treatment is successful only in recent fissures and consists of laxatives, hot baths, local healing ointments and analgesics. On the other hand, chronic anal fissure needs surgical intervention in the form of sphincterotomy with or without fissurectomy. Reports of jojoba oil indicated its anti-inflammatory and anti bacterial effects, beside being non-toxic and non-carcinogenic. This encouraged us to try the use of jojoba oil rectal suppositories in treatment of acute and chronic anal fissures.

Anal fissures are commonly encountered in routine colorectal practice. An anal fissure is a split in the mucosa of the distal anal canal. Young adults of both sexes are affected equally. Patients present with anal pain commonly during defecation and/or rectal bleeding.

Whilst acute anal fissures usually heal spontaneously or with simple therapeutic measures, some progress to form a chronic linear ulcer. The chronicity of a fissure relates to duration greater than 6 weeks with fibers of the internal anal sphincter visible at the base of the fissure. Associated pathology may include a "sentinel pile" distally and a fibro-epithelial polyp may from at the apex.

Most anal fissures are idiopathic with no identifiable underlying disease process. There is no simple or unified theory to explain their genesis, though constipation and lack of dietary fibers are implicated.

Most fissures occur in the posterior midline; this may be anatomically related to a lack of tissue support posteriorly within the anal canal. Fissures associated with pregnancy are commonly located anteriorly and are often associated with low anal canal fissures. Other causes of fissures include Crohn's disease, ulcerative colitis, syphilis, human immunodeficiency virus (HIV), or Tuberculosis. These are secondary fissures and are most appropriately treated by addressing the underlying disease process.

The initial approach in the treatment of anal fissures in non-operative. An acute anal fissure may heal spontaneously or in response to medical therapy with warm baths, stool softeners, bulk laxatives, analgesics, topical anesthetics and reassurance.
The term "chemical sphincterotomy" refers to the pharmacological manipulation of anal sphincter tone to promote healing of fissure without permanently disrupting normal sphincter function. Examples are Nitric oxide donors (GTN) and calcium channel antagonists.

The aim of this work is to evaluate the response of patients suffering from acute and chronic anal fissure to the treatment with jojoba oil rectal suppositories (Jobacure) produced by SEDICO. This was done through studying its efficacy and safety as an alternative to other surgical and chemical methods of treatment.

Jojoba is a perennial woody shrub grown primarily in the desert regions of the south western United States and north western Mexico. Native Americans have long used jojoba oil to help healing sores and wounds. Today, jojoba oil is still most commonly used for cosmetic purposes, particularly for the maintenance of healthy skin.

Jojoba oil helps promote healing of skin in many ways. It has an antimicrobial property which means that it acutely discourages the growth of some bacterial and fungal microbes that attack the skin. Furthermore, the chemical composition of Jojoba closely resembles that of the skins natural sebum. Hence, it is easily absorbed and rarely causes allergic reaction even in the most sensitive individuals.

Jojoba oil contains many important nutrients such as vitamin $\mathrm{E}$ and $\mathrm{B}$ complex vitamins in addition to some minerals as silicon, chromium, copper and zinc. It also contains a lot of Iodine which may be where jojoba gets its ability to fight against bacterial and fungal infections.

There are other medical conditions where jojoba oil is also applicable such as the treatment and prevention of vagintis to relieve dysmenorrhea and nipple cracks. It is also used in treatment of eye diseases as well as inflammations of internal middle or external ear. It has been effectively used it treating gingivo-stomatitis toothache and rheumatic arthritis.

Finally, jojoba oil has its application in general surgery. It is used successfully in the treatment of anal fissures, hemorrhoids, and early stages of varicose veins.

\section{Patients and methods}

This study comprised 100 patients of different age 
and sex suffering from acute and chronic anal fissures presented to the outpatient clinics in Ain Shams University hospitals (Al-Demerdash) and Ain Shams University Specialized Hospital (ASUSH) during the period between July 2008 and June 2009.

All patient where subjected to a full clinical history and examination including per rectal examination. The full clinical history stressed on pain character, its onset, what provocates and what relieves it, and the intensity of pain which was recorded as a scale of 0 to 10. Bleeding, pruritus ani, and continence grade where also recorded if present.

We excluded patients who proved to have fissures associated with other diseases ulcerative colitis, Crohn's disease, hemorrhoids, fistulae and suppuration, as well as those who had malignant anal conditions. Patients who had previous surgery for anal fissure were excluded from out study as well.

Written informed consent was obtained from each subject selected for this study. The informed consent form described the aim of study, the procedure to be followed as well as the risk and benefits of participation. A copy of consent was given to each patient.

In this randomized blind comparative study (clinical trial), using randomization tables, we divided the patients into two equal groups: group A (control group) received Ansuol rectal suppositories (bismuth subgalate + Zinc Oxide + Bismuth oxide); while group B were given jojoba oil in the form of rectal suppositories (Jobacure produced by SEDICO).

Patients in both groups were instructed to use the given medication every 12 hours until symptoms free. All patients were given suppositories in especially coded envelopes after removing any cover indicating the trade name of the medication.

On the initial visit, the clinical investigator explained the study protocol to the patient and asked him/her if he/she was interested to share in the clinical trial as well as a clinical recode of the clinical symptoms as pain, bleeding, constipation and discharge. The record included the degree of severity (scaled from 0-10 subjectively) and duration of each symptom.

Follow up visits were appointed two weeks after the initial treatment then four weeks later. In each visit the same clinical symptoms were reviewed and recorded similarly as before treatment. After the second follow up visit patients were checked clinically regarding any reported discomfort or side effects whether local or systemic.

\section{Statistical analysis of the data:}

Data was qualitative and expressed as frequency (\%). Our data was statistically analyzed using a personal computer supplied with the statistical package of social sciences (SPSS-VERG) software and Microsoft Excel 4.0 statistical software.

The person chi square test was used to compare qualitative data between group $A$ and group $B$.

Significance was measured at the 0.05 level, with confidence internal $95 \%$ so that $P$ value $>0.05$ is not significant while $P$ value $<0.05$ is significant.

\section{Results}

No patient was dropped out of the study, and none had adverse events that necessitated removing the blinding from the study.

Our patients were divided into two equal groups of 50 patients in each. Group A received treatment with Anusol suppositories, while group $B$ received Jobacure suppositories for treatment. The mean age $23.7(\mu 6.8)$ and $22.9(\mu 7.3)$ years were in group A \& B respectively (Table 1).

Pain, as assessed symptomatically before treatment, was stabbing in 35 patients of group $A$ and in 40 patients of group $B$ and was dull aching in 15 patients of group $A$ and in 10 patients of group $B$ with no significant difference between both groups.

Pain was sudden onset (acute fissure) in 18 patients of group $A$ and in 22 patients of group $B$ and was gradual onset (chronic fissure) in 32 patients of group $A$ and in 28 patients of group B with no significant difference between both groups. Hard stools was provocating factor in 33 patients of group A and in 32 patients of group $B$ while constipation was provocating factor in 17 patients of group $A$ and in 18 patients of group $B$ which was statically insignificant.

Regarding duration of disease in weeks, it was $15.9(\mu 7.2)$ in group A and $15.7(\mu 7.4)$ in group B (Chart 2).

Table 1: Patients demographics

\begin{tabular}{lccc}
\hline & Group A & Group B & P value \\
\hline Age & $23.7(6.8)$ & $22.9(7.3)$ & 0.572 \\
Sex & Male: Female $=29: 21$ & Male: Female $=27: 23$ & 0.840 \\
\hline
\end{tabular}




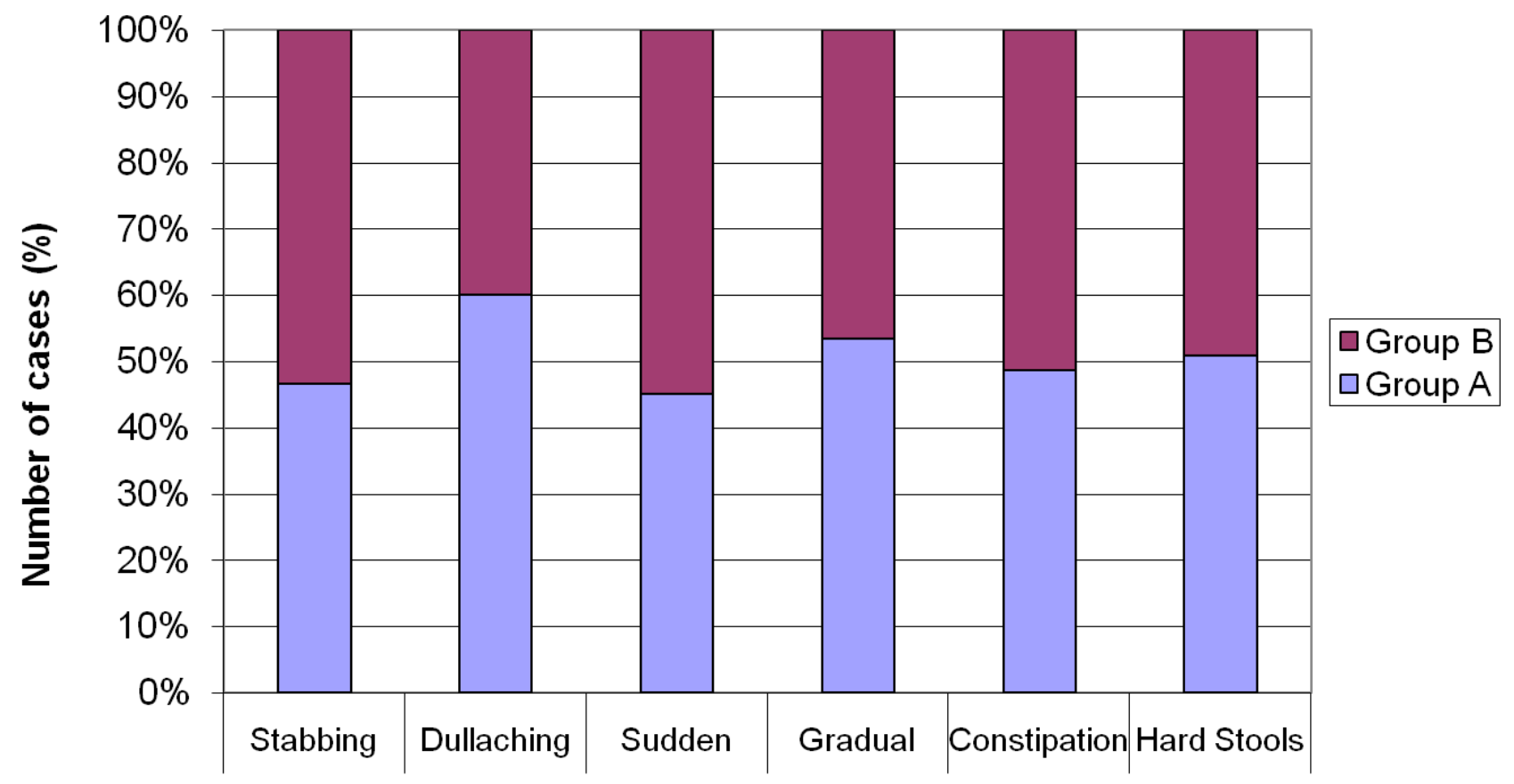

Chart 1: P ain criteria before treatment.

Table 2: Analysis of pain before treatment

Analysis of pain before starting treatment

\begin{tabular}{|c|c|c|c|c|c|}
\hline & & Group A & Group B & Total & P value \\
\hline \multirow{2}{*}{ Character } & Stabbing & 35 & 40 & 75 & \multirow{2}{*}{0.356} \\
\hline & Dullaching & 15 & 10 & 25 & \\
\hline \multirow{2}{*}{ On set } & Sudden & 18 & 22 & 40 & \multirow{2}{*}{0.541} \\
\hline & Gradual & 32 & 28 & 60 & \\
\hline \multirow{2}{*}{ Waht Increase? } & Constipation & 17 & 18 & 35 & \multirow{2}{*}{1.000} \\
\hline & Hard Stools & 33 & 32 & 65 & \\
\hline \multicolumn{2}{|c|}{ Duration in weeks } & $15.0(7.2)$ & $15.7(7.4)$ & & 0.891 \\
\hline
\end{tabular}

Severity of pain was graded from 0 to 10 as described by the patient. In cases with acute anal fissures it was analyzed in both groups. Before treatment; in group (A) score was 4 in 1 patient, 5 in 1 patient, 6 in 3 patients, 7 in 5 patients, 8 in 6 patients and 9 in 2 patients. In group (B) it was 4 in 4patients, 5 in 2 patients, 6 in 4 patients, 7 in 7 patients and 8 in 5 patients with no significant difference between both groups (Table 3 ).

Two weeks following application, severity of pain was greatly diminished in both groups as following: In group (A) (the Anosol group), 5 patients had no pain, while it was grade 1 in 3 patients, grade 2 in 4 patients and grade 3 in 4 patients, and 4 in 2 patients. In group
(B) (the Jobacure group) 8 patients had no pain while grade 1 in 6 patients, grade 2 in 4 patients, grade 3 in 2 patients and grade 4 in 2 patients. Pain was significantly lower after application in group (B) than (A).

Four weeks following application, severity of pain was greatly diminished in both groups as following: In group (A), 8 patients had no pain while grade 1 in 6 patients, grade 2 in 3 patients and grade 3 in 1 patient. In the other group (B), 16 patients had no pain while it became grade 1 in 4 patients, grade 2 in 2 patients. Pain was again significantly lower after application in group (B) than (A) (Chart 3). 


\begin{tabular}{ccccccc}
\hline & \multicolumn{3}{c}{ Group A } & \multicolumn{4}{c}{ Group B } \\
\hline GRADE & Preapplication & $\begin{array}{c}\text { 2wk } \\
\text { Postapplication }\end{array}$ & $\begin{array}{c}\text { 4wk } \\
\text { Postapplication }\end{array}$ & Preapplication & $\begin{array}{c}\text { 2wk } \\
\text { Postapplication }\end{array}$ & $\begin{array}{c}\text { 4wk } \\
\text { Postapplication }\end{array}$ \\
\hline 0 & - & 5 & 8 & - & 8 & 16 \\
1 & - & 3 & 6 & - & 6 & 4 \\
2 & - & 4 & 3 & - & 4 & 2 \\
3 & - & 4 & 1 & - & 2 & - \\
4 & 1 & 2 & - & 4 & 2 & - \\
5 & 1 & - & - & 2 & - & - \\
6 & 3 & - & - & 4 & - & - \\
7 & 5 & - & - & 7 & - & - \\
8 & 6 & - & - & 5 & - & - \\
9 & 2 & - & - & - & - & - \\
10 & - & - & - & - & - & 22 \\
Total & 18 & 18 & 18 & 22 & 22 & - \\
\hline
\end{tabular}

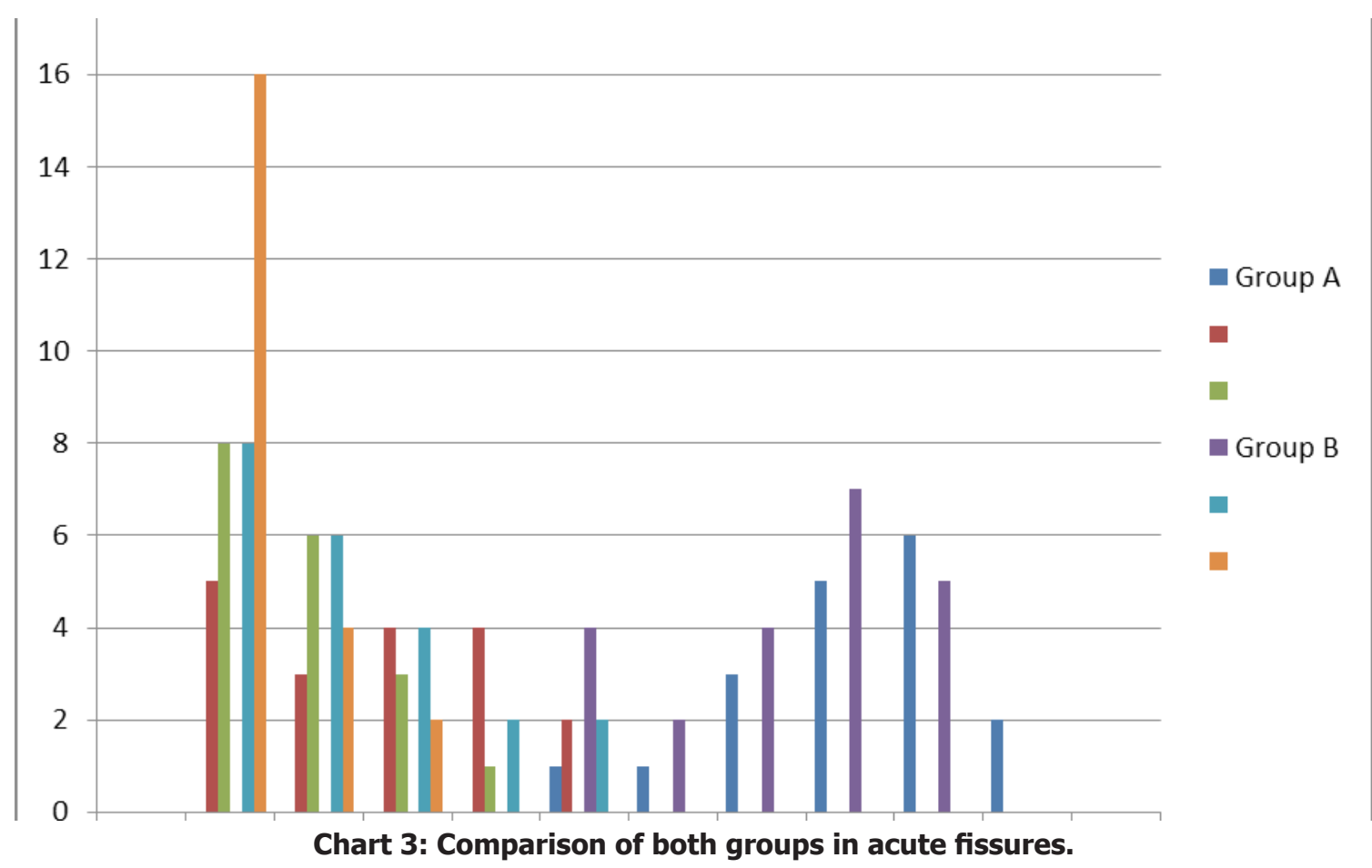

As demonstrated in Table 4, pain in cases with chronic anal fissures was analyzed in both groups. Before treatment, in group (A) score was 4 in 6 patients, 5 in 5 patients, 6 in 7 patients, 7 in 8 patients and 8 in 6 patients. In group (B), it was 4 in 4 patients, 5 in 3 patients, 6 in 5 patients, 7 in 6 patients, 8 in 8 patients and 9 in 2 patients, with no significant difference between both groups.

Two weeks following application, severity of pain was diminished in both groups. In group (A), although pain severity decreased no patient was free of pain. It became grade 1 in 2 patients, grade 2 in 4 patients, grade 3 in 6 patients, 4 in 8 patients, 5 in 7 patients and 6 in 5 patients. In group (B), 2 became free of pain, while grade 1 in 3 patients, grade 2 in 5 patients, grade 3 in 8 patients, grade 4 in 5 patients and grade 5 in another 5 patients. Pain was significantly lower after application in group (B) than (A).

Four weeks following application, severity of pain was diminished in both groups. In group(A),2 patients had no pain, while grade 1 in 4 patients, grade 2 in 8 patients, grade 3 in 10 patients and 4 in 8 patients. In group (B), 4 patients had no pain, while it became grade 1 in 4 patients, grade 2 in 8 patients, grade 3 in 9 patients and grade 4 in 3 patients .Pain was significantly lower after application in group (B) than (A) (Chart 4). 


\begin{tabular}{ccccccc}
\hline & \multicolumn{3}{c}{ Group A } & \multicolumn{4}{c}{ Group B } \\
\hline Grade & Preapplication & $\begin{array}{c}\text { 2wk } \\
\text { Postapplication }\end{array}$ & 4wk Postapplication & Preapplication & $\begin{array}{c}\text { 2wk } \\
\text { Postapplication }\end{array}$ & $\begin{array}{c}\text { 4wk } \\
\text { Postapplication }\end{array}$ \\
\hline 0 & - & - & 2 & - & 2 & 4 \\
1 & - & 2 & 8 & - & 3 & 4 \\
2 & - & 4 & 10 & - & 5 & 8 \\
3 & - & 6 & 8 & - & 8 & 9 \\
4 & 6 & 8 & - & - & 5 & - \\
5 & 5 & 7 & - & 3 & 5 & - \\
6 & 7 & 5 & - & 5 & - & - \\
7 & 8 & - & - & 6 & - & - \\
8 & 6 & - & - & 2 & - & - \\
9 & - & - & - & - & - & - \\
10 & - & 32 & - & 28 & 28 & 28 \\
\hline
\end{tabular}

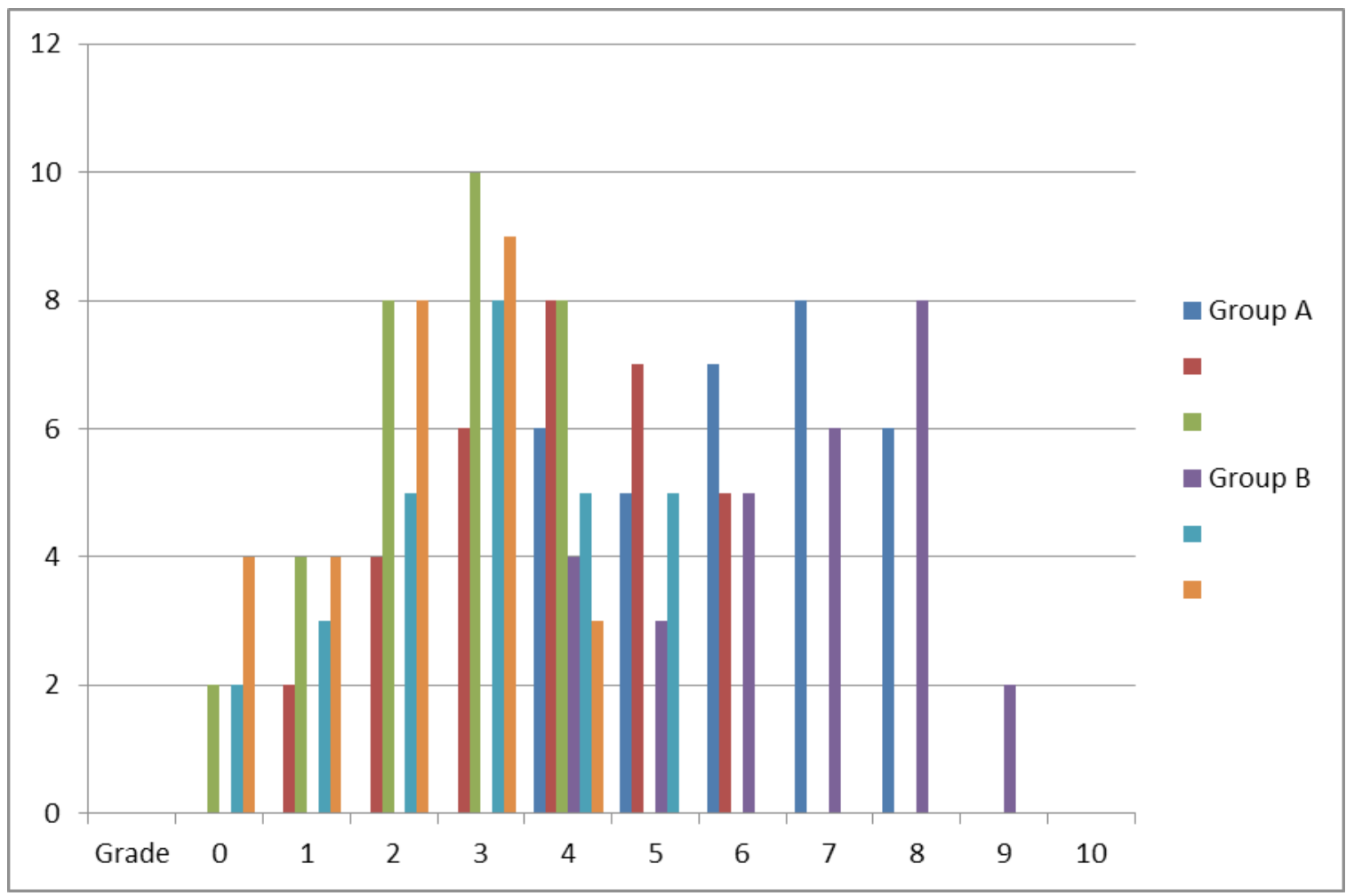

Chart 4: Comparison of both groups in chronic fissures.

Pruritis ani was found in 40 patients before application of suppositories, 17 of them was in group A and 23 in group $B$.

Two weeks following application, Pruritis ani was greatly diminished in both groups as follows: in group A, it was only found in 9 patients, while in the other group
Pruritis ani persisted in only 5 patients with significant difference. After 4 weeks following application, Pruritis ani in group $A$, the anosol group was found only in 4 patients, and in only 2 patients in group (B) with no significant difference between both groups (Table 5). Jobacure was found to control pruritis ani better than Anusol. 
Table 5: Symptoms changes after treatment

\begin{tabular}{cccccccc}
\hline & \multicolumn{3}{c}{ Group A } & \multicolumn{2}{c}{ Group B } \\
\hline & Preapplication & $\begin{array}{c}\text { 2wk } \\
\text { Postapplication }\end{array}$ & $\begin{array}{c}\text { 4wk } \\
\text { Postapplication }\end{array}$ & Preapplication & $\begin{array}{c}\text { 2wk } \\
\text { Postapplication }\end{array}$ & $\begin{array}{c}\text { 4wk } \\
\text { Postapplication }\end{array}$ & $\begin{array}{c}\text { P } \\
\text { value }\end{array}$ \\
\hline $\begin{array}{c}\text { Bleeding } \\
\begin{array}{c}\text { Prurits } \\
\text { Ani }\end{array}\end{array}$ & 17 & $5^{*}$ & $2 *$ & 18 & $3^{*}$ & 0.145 & 0.122 \\
\hline
\end{tabular}

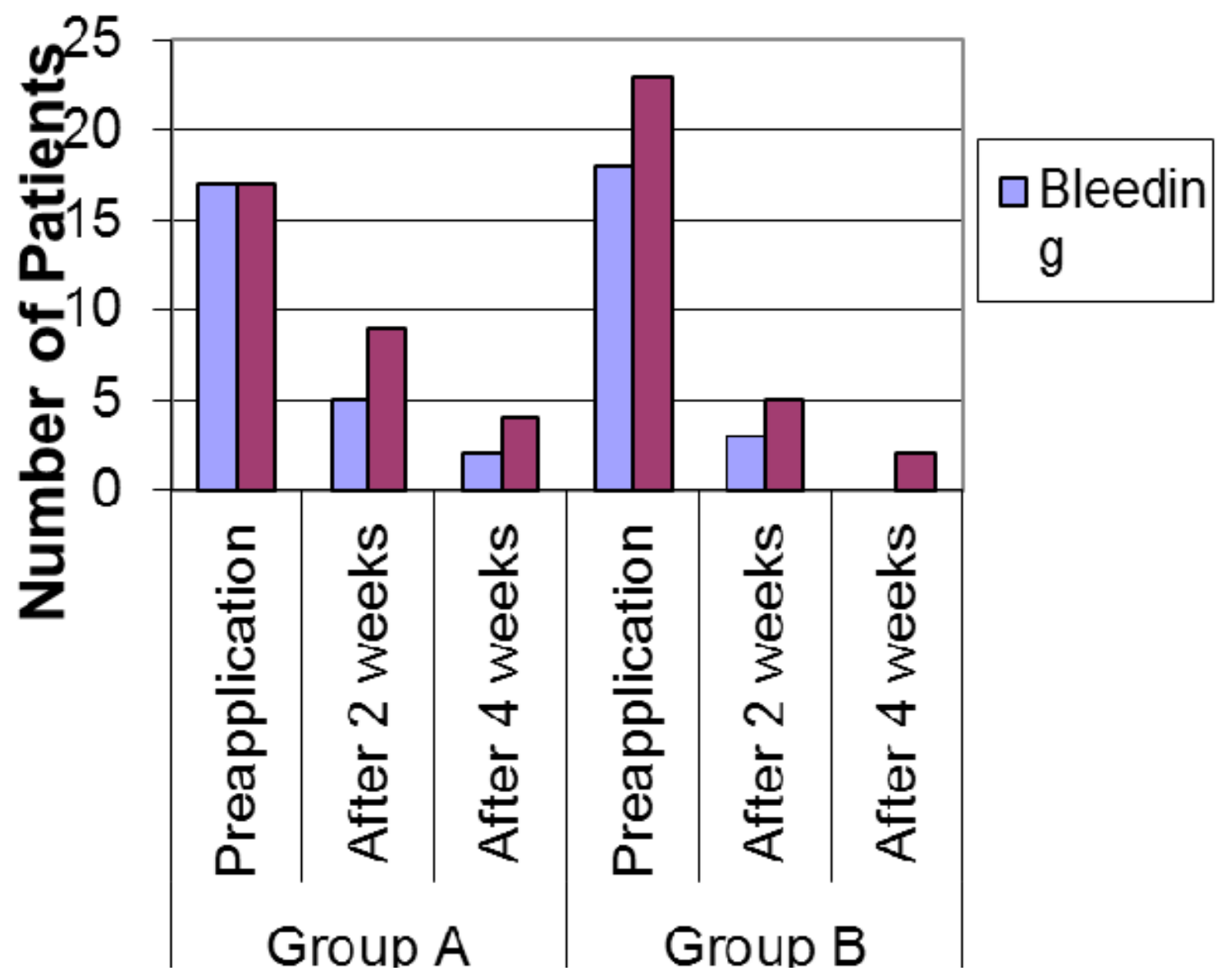

Chart 5: Response to treatment in both groups. 


\section{Discussion}

Anal fissure is a common and benign disease. The associated discomfort is more annoying than dangerous in otherwise healthy people. Most acute anal fissures heal spontaneously or with conservative treatment. ${ }^{1,9,12}$

Fissures are considered chronic when they persist with symptoms for longer than six to eight weeks, and other modes of treatment are usually indicated. It has been suggested that chronic anal fissures are associated with increased pressure of the internal anal sphincter, ${ }^{2}$ and that they have an ischemic origin because of poor blood supply. ${ }^{3}$

Reduction of anal sphincter pressure by sphincterotomy improves ano-dermal blood flow at the posterior midline, which results in fissure healing. ${ }^{3}$

Surgical sphincterotomy results in healing for up to 95 percent of patients, but the postoperative period may be marked by surgical risks, complications, and a late incidence of incontinence in a few patients. ${ }^{1,4-5,13}$

Recently, new pharmacologic methods have been used to create a reversible sphincterotomy. Local injection of botulinum toxin and topical application of glyceryl trinitrate or isosorbide dinitrate have been used to decrease anal sphincter pressure until the fissure has healed. These pharmacologic methods have shown similar rates of healing of anal fissures and have been shown to be superior to placebo. ${ }^{6,8}$

There is one randomized trial that supports the use of both glyceryl trinitrate and botulinum toxin in the treatment of chronic anal fissure. After 2 months, fissures had healed in 96 percent of patients treated with botulinum toxin and in 60 percent of those treated with glyceryl trinitrate. ${ }^{14}$

However, injection of botulinum toxin is expensive and requires injection of the toxin into the internal anal sphincter; transitory fecal incontinence and perianal thrombosis have been reported. ${ }^{6,715}$

Glyceryl trinitrate ointment is inexpensive and requires less skill to apply; however, the risk of recurrence and poor longterm outcomes are significant in patients treated with glyceryl trinitrate, and side effects (occasional loss of flatus, anal burning, tachyphylaxis, and transient headaches because of systemic absorption) have been reported. ${ }^{10,11,13,14,17}$

Nifedipine, a dihydropyridine, is a calcium antagonist that at present is only administered orally for cardiovascular disorders. ${ }^{18}$

Jojoba Oil may be used in the treatment of and preventative measures associated with general surgery, as well as in the treatment of eye diseases, inflammation of the internal, middle or external ear, rheumatic pain and arthritis, gingivostomatitis, toothache and dermal diseases.
Jojoba oil is a natural product and is characterized by being non-irritant and non-allergic to skin and mucous membrane. This oil has lubricant, moisturizing and soothing properties, as well as having anti-bacterial, anti-inflammatory and anti-oxidant properties. It has a very high healing power and improves blood circulation, and also has high penetration into stratum corneum.

Jojoba Oil also provides skin protection as it has antiallergic properties, disinfectant, and produces cell stimulation, skin regeneration and stops inflammation. The $\mathrm{pH}$ of Jojoba oil is balanced and reveals beneficial effects for dry and damaged skin.

It has been effectively used as suppositories in treatment of acute and chronic anal fissure and anal fistula, as well as the treatment of prostatits, Hemorrhoids (at $2^{\text {nd }}$ degree).

The present study investigated local use of jojoba oil, in the form of an suppositories, for treatment of acute \& chronic anal fissure. A prospective, double blind study reported healing of the fissure in percent of 100 consecutive patients with acute and chronic anal fissure, 50 of them were treated with Anosol and the other 50 with jobacure after 2 to 4 weeks of treatment with topical jojoba oil.

Topical jojoba oil medicaments have shown efficacy in relieving patients of anal pain and in healing acute \& chronic anal fissure.

These end points were achieved early at two weeks of treatment and preceded the significant healing rate of acute \&chronic anal fissure observed in the Anosol group at four weeks of treatment.

No patient treated with jobacure showed any systemic side effect or significant anorectal bleeding or withdrew from the study.

Data reported in the present study cannot justify this assumption, and further studies are required to explain the mechanism of healing of fissure.

\section{Conclusion}

Local application of Jojoba oil proved to be effective in treating acute anal fissure. It abolishes pain and straining, and the acute ulcer heals completely. A laxative is recommended with treatment to avoid hard stools that might delay the healing process.

In chronic anal fissure, Jojoba oil succeeds in relieving the symptoms to some extent, but it needs a longer term of therapy to relieve symptoms completely. However, it does not heal the pathological chronic ulcer and symptoms are apt to recurrence.

We recommend the use of Jobacure suppositories in the treatment of acute anal fissure aiming at full cure. The recommended dose is one suppository/ 12 hours for 2 weeks. 
It is also recommended in chronic fissure to relieve the subjective symptoms but for longer period of time. The recommended dose is one suppository/ 12 hours plus additional suppository after defecation for 2-4 weeks according to severity of symptoms. Surgery is preserved for patients with residual symptoms after sufficient treatment.

\section{References}

1. Lund JN, Scholefield JH: Aetiology and treatment of anal fissure. Br J Surg. 1996; 83: 1335-44.

2. Farouk R, Duthie GS, MacGregor AB, Bartolo DC: Sustained internal sphincter hypertonia in patients with chronic anal fissure. Dis Colon Rectum. 1994; 37: 424-9.

3. Schouten WR, Briel JW, Auwerda JJ, De Graaf EJ: Ischaemic nature of anal fissure. Br J Surg. 1996; 83: 63-5.

4. Oh C, Divino CM, Steinhagen RM: Anal fissure: 20-year experience. Dis Colon Rectum. 1995; 38: $378-82$.

5. Nyam DC, Pemberton JH: Long-term results of lateral internal sphincterotomy for chronic anal fissure with particular reference to incidence of fecal incontinence. Dis Colon Rectum. 1999; 42: 1306-10.

6. Jost WH: One hundred cases of anal fissure treated with botulin toxin: Early and long-term results. Dis Colon Rectum. 1997; 40: 1029-32.

7. Maria G, Cassetta E, Gui D, Brisinda G, Bentivoglio AR, Albanese A: A comparison of botulinum toxin and saline for the treatment of chronic anal fissure. N Engl J Med. 1998; 338: 217-20.

8. Kennedy ML, Sowter S, Nguyen H, Lubowski DZ: Glyceryl trinitrate ointment for the treatment of chronic anal fissure: Results of a placebo-controlled trial and longterm follow-up. Dis Colon Rectum. 1999; 42: 1000-6.

9. Antropoli C, Perrotti $P$, Rubino $M$, et al: Nifedipine for local use in conservative treatment of anal fissures: Preliminary results of a multicenter study.
Dis ColonRectum. 1999; 42: 1011-5.

10. Altomare DF, Rinaldi M, Milito G, et al: Glyceryl trinitrate for chronic anal fissure-healing or headache? Results of a multicenter, randomized, placebocontrolled, double-blind trial. Dis Colon Rectum. 2000; 43: 174-81.

11. Carapeti EA, Kamm MA, McDonald PJ, Chadwick SJ, Melville D, Phillips RK: Randomized controlled trial shows that glyceryl trinitrate heals anal fissures, higher doses are not more effective, and there is a high recurrence rate. Gut. 1999; 44: 727-30.

12. Jensen SI: Treatment of first episodes of acute anal fissure: prospective randomized study of lignocaine ointment versus hydrocortisone ointment or warm sitz baths plus bran. Br Med J. 1986; 292: 1167-9.

13. Khubchandani IT, Reed JF: Sequelae of internal sphincterotomy for chronic anal fissure in ano. $\boldsymbol{B r} \boldsymbol{J}$ Surg. 1989; 76: 431-4.

14. Brisinda G, Maria G, Bentivoglio AR, Cassetta $E$, Gui $D$, Albanese A: A comparison of injections of botulinum toxin and topical nitroglycerin ointment for the treatment of chronic anal fissure. $N$ Engl $\boldsymbol{J}$ Med. 1999; 341: 65-9.

15. Jost WH, Schanne S, Militz H, Schimrigk K: Perianal thrombosis following injection therapy into the external anal sphincter using botulin toxin [letter]. Dis Colon Rectum. 1995; 38:781.

16. Richard CS, Gregoire R, Plewes EA, et al: Internal sphincterotomy is superior to topical nitroglycerin in the treatment of chronic anal fissure: results of a randomized, controlled trial by the Canadian Colorectal Surgical Trials Group. Dis Colon Rectum. 2000; 43: 1048-58.

17. Bacher $\mathrm{H}$, Mischinger $\mathrm{H}-\mathrm{J}$, Werkgartner $\mathrm{G}$, et al: Local nitroglycerin for treatment of anal fissures: an alternative to lateral sphincterotomy? Dis Colon Rectum. 1997; 40: 840-5.

18. Triggle DJ: Calcium, calcium channels, and calcium\ channel antagonists. Can J Physiol Pharmacol. 1990; 68: 1474-81. 